Available online at www.jmle.org

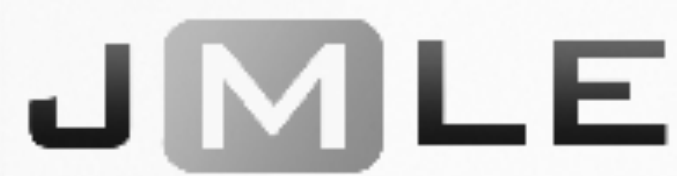

The National Association for Media Literacy Education's

Journal of Media Literacy Education 10 (1), 104 - 123

\title{
What Do Preservice Teachers Think about Teaching Media Literacy? An Exploratory Study Using the Theory of Planned Behavior
}

\author{
Sarah Gretter and Aman Yadav \\ Michigan State University
}

\begin{abstract}
Despite the numerous benefits of media \& information literacy for students in today's digital society, the lack of teacher preparation in teaching media and information literacy skills suggests a gap between the societal rationale for students becoming media literate and the sustainable preparation of teachers. The purpose of this exploratory study was to explore the factors and beliefs underlying preservice teachers' intention to teach media and information literacy in their future classroom according to the theory of planned behavior. Findings suggest that although preservice teachers' have positive attitudes towards media and information literacy as an essential skill for students, they do not feel that it is highlighted in their teacher education program and many do not see other stakeholders including faculty, school administrators and parents as encouraging it. Instructor modeling of media and information literacy may be needed to help preservice teachers develop confidence in integrating it into their future work.
\end{abstract}

KEYWORDS: media and information literacy, teacher education, preservice teachers, digital media

Today, the overwhelming majority of teenagers report going online on a daily basis through participation in digital media-particularly on social media such as blogs, social networks, forums, or video sharing websites (Boulianne 2015; Lenhart 2015). Consequently, students come across large amounts of unfiltered information online, and recent studies have showed that they can have difficulties distinguishing between real and fake information (Stanford History Education Group 2016). National and international policy efforts are advocating that it has become essential for $21^{\text {st }}$ century students to possess media and information literacy (MIL) - the set of competencies they need to critically evaluate information communicated through different multimedia sources (International 
Society for Technology in Education 2015; Partnership for $21^{\text {st }}$ century 2014; Wilson et al. 2013).

While public awareness about online misinformation is growing and MIL skills are progressively incorporated into educational standards (e.g., Next Generation Science Standards; Common Core Standards; College, Career and Civic Life for Social Studies Framework), the mere existence of teacher training in MIL and MIL pedagogies remains blurry (Earp 2009; Hobbs 2007; Kovalik, Jensen, Schloman and Tipton 2011). Indeed, Tiede et al. (2015) examined teacher education courses at 316 universities in the United States and found that media literacy education was not consistently integrated in teacher preparation, even though institutions like UNESCO agree that "initial focus on teachers is a key strategy to achieving a multiplier effect: from information-literate teachers to their students and eventually to society at large" (Wilson et al. 2013, 17). There is therefore an urgent need to address the lack of connection between the need for preservice training in MIL and the absence of MIL integration in teacher training.

Furthermore, if the majority of preservice teachers are themselves students who grew up in this age of digital media, yet are not trained to teach MIL through their teacher education programs, do they see the relevance of MIL skills? Do they intend to teach these skills in their future classrooms? Research has showed that exposure to technology and fluency in digital media use does not imply that preservice teachers are inherently knowledgeable about it (Hargittai 2010). Lindstrom, Schmidt-Crawford and Thompson (2016) noted that although preservice teachers are increasingly more equipped with technological skills, they "continue to have little experience and vision for how to use digital technologies in ways that develop the digital literacies their students need to fully participate in the public, private, and economic spheres that characterize contemporary society" (3).

Prior research has also demonstrated that familiarity with digital media does not always translate into preservice teachers' use of technology-related pedagogies in their own classrooms (Kinash, Wood and Knight 2013; Russell, Bebell, O'Dwyer and O'Connor 2003). Teacher competence is only one of several factors influencing teachers' decision to teach with and about technology (Shiue 2007; Teo and Lee 2010; Teo 2012; Valtonen et al. 2015). Other influences such as attitude (i.e., they might not teach MIL if they do not value it), and the opinion of others (i.e., they might be inclined to teach MIL if professors encourage it) may also play an important role in determining their intentions to teach MIL in their future classroom (Lee, Cerreto and Lee 2010). The present exploratory study aimed to look at preservice teachers' perspectives about teaching media \& information literacy in their future classroom under the framework of the theory of planned behavior (TPB). The model was developed in an effort to describe the influences impacting individuals' behavioral decisions, while identifying both the direct and indirect determinants of individuals' intentions to perform a behavior (Ajzen 1991). 


\section{Theoretical Background}

The theory of planned behavior (TPB) is commonly used to predict behaviors and design interventions to impact decision-making (Ajzen 1991). As shown in Figure 1 below, the theory explains that the immediate antecedent of a behavior is the individual's intention to perform it. This intention, in turn, is a function of three independent factors: (1) attitudes, (2) subjective norms, and (3) perceived behavioral control. In other words, to predict whether a person intends to perform a behavior, we need to know (i) whether the person is in favor of doing it, (ii) how much social pressure the person feels to do it, and (iii) whether the person feels in control of the behavior in question (Francis et al. 2004). In addition to these direct determinants, the TPB identifies the behavioral, normative, and control beliefs that underlie the constructs of attitude, subjective norms, and perceived behavioral control (Ajzen 1991).

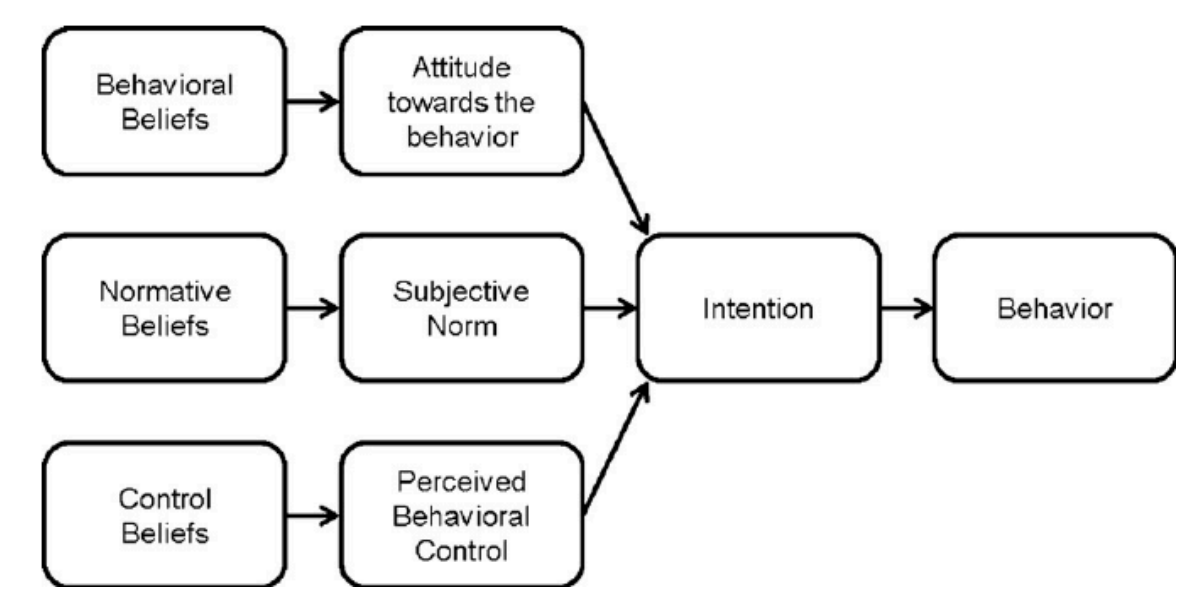

Figure 1. Theory of Planned Behavior (adapted from Ajzen 1991)

The advantage of the TPB approach is that it helps identify both the direct determinants and the underlying beliefs that impact individuals' intention to perform or not perform a specific behavior (Fancis et al. 2004). For instance, the model has been previously applied to educational technology in order to predict faculty decisions to adopt Web 2.0 technologies (Ajjan and Hartshorne 2008), teachers' use of educational technology (Lee, Cerreto and Lee 2010), preservice teachers' intentions to use and use of technology (Shiue 2007; Teo and Lee 2010; Teo 2012; Valtonen et al. 2015), preservice teachers' intentions to use Web 2.0 technologies (Sadaf, Newby and Ertmer 2012), student teachers' and experienced teachers' computer usage (Smarkola 2008). As such, the TPB framework allows researchers to gain an understanding of the behavior in question by tracing its determinants back to their underlying beliefs.

\section{Research Aims and Methods}

The goal of the present studies was two-fold: (1) to identify direct determinants of preservice teachers' intention to teach media \& information literacy in their future classrooms. To that effect, we conducted an exploratory 
study using interview data to identify preservice teachers' attitudes, subjective norms, and perceived behavioral control about teaching media \& information literacy in their future classroom. We aimed (2) to elicit indirect beliefs held by preservice teachers about teaching media \& information literacy in their future classrooms. For this purpose, we conducted an elicitation study through focus groups, aiming to evoke the behavioral, normative, and control beliefs they associated with teaching media \& information literacy in their future classroom. Each study is further described below.

\section{Study One}

This exploratory study aimed to identify the direct determinants of preservice teachers' intention to teach media \& information literacy in their future classroom based on the Theory of Planned Behavior - namely attitudes, subjective norms, and perceived behavioral control. In this study, we asked: What are preservice teachers' attitudes, subjective norms, and perceived behavioral control about teaching media \& information literacy in their future classroom?

Participants. Nineteen elementary and secondary preservice teachers enrolled in a teacher education program at a large Midwestern university participated in the first study. A maximum variation sample was used in order to include individuals with different perspectives on the same phenomenon (Hatch 2002). Participants included 14 females and five males. There were ten first-year teacher education students, one sophomore, two juniors, and six seniors. Of the 19 participants, 12 were elementary education majors, and seven were secondary education majors. The sample size was based on data saturation, where sample size was deemed adequate when the data shed sufficient light on the phenomenon being studied (Mason 2010). Specifically, data was gathered until no new insights regarding participants' perspectives about MIL education emerged from qualitative coding of the interview data, which was done concurrently with the data collection (Charmaz 2006).

Measures. A semi-structured interview protocol was used to get an indepth understanding of preservice teachers' views about teaching MIL (Creswell 2013). The questions were designed to identify preservice teachers' attitudes, subjective norms, and perceived behavioral control about teaching MIL in their future classroom. A semi-structured interview protocol was designed with a predetermined set of open questions to prompt discussion about the three determinants of the TPB (Appendix A), with opportunities for the interviewer to further explore specific themes or responses.

Procedure. The study was advertised through flyers across the college of education to recruit preservice teachers. Prospective participants who responded to the announcement were contacted by the researcher to set up an interview. The interviews started with a brief description of MIL. On average, the interviews lasted 36 minutes and were tape-recorded for transcription. During the interview, participants responded to open-ended questions based on the semi-structured interview protocol. Participants were then remunerated with a fifteen-dollar Amazon gift card.

Data Analysis. The interviews were transcribed and imported into the 
qualitative analysis software NVivo. The software was used to conduct a content analysis of the data in order to facilitate the discovery of the themes, patterns, as well as subtle messages preservice teacher attributed to MIL. Specifically, NVivo allowed for the detailed line-by-line analysis needed to identify themes and suggest relationships among generated codes (Corbin and Strauss 2014). The codes helped to draw inferences in the context surrounding their perspectives of MIL (Hoffman, Wilson, Martínez and Sailors 2011). The qualitative analysis generated an initial list of 56 codes, which were collapsed into three conceptual themes related to MIL education: (i) attitudes, (ii) subjective norms, and (iii) perceived behavioral control. In order to establish reliability of the codes, intercoder agreement was conducted with an additional coder. The second coder was trained using the coding scheme and then independently coded $30 \%$ of the data using the coding scheme. The agreement rate was $93.75 \%$, which was deemed sufficient to continue the data analysis with the original coder's scheme.

\section{Results}

The data gathered from the interviews was organized into the three TPB determinants (i.e., attitudes, subjective norms, and perceived behavioral control) related to preservice teachers' perspectives about teaching MIL in their future classroom.

Attitudes. Preservice teachers in our sample had positive attitudes about media literacy. Altogether, most preservice teachers $(\mathrm{N}=17)$ demonstrated a positive attitude about how MIL skills could benefit student learning about digital media and information. More importantly, participants $(\mathrm{N}=18)$ communicated that MIL practices were important elements of a school curriculum. A number of participants $(\mathrm{N}=10)$ discussed the relevance of digital media in today's society, and highlighted the need to draw upon and incorporate the prevalence of digital media in students' lives into lesson plans. For example, one participant succinctly summarized this point, stating, "the nature of how kids are communicating nowadays, is just becoming second nature for them, it's a part of their culture, so why not incorporate it in the classroom, it can help them understand things better." Most preservice teachers $(\mathrm{N}=15)$ recognized that MIL could have longterm effects on students' academic and professional skills and agreed that MIL was a valuable skill both in the workforce and in students' personal lives. One participant pointed out the importance of media literacy for students' careers by explaining:

I think it teaches you to be open-minded, number one, 'cause that's going to be huge and the working field likes to be open-minded. If you're not, it just makes it very difficult for anyone to work with you. So, it's good to be open-minded and be open to different opinions.

Additionally, preservice teachers acknowledged that MIL was positive for students' personal growth. A number of preservice teachers $(\mathrm{N}=12)$ recognized that MIL could help students develop social skills both online and offline. For 
instance, a participant discussed how students' exposure to different perspectives on social media had become a reality:

I know these types of videos and blog posts on Buzzfeed and Facebook, they usually have a lot of likes, a lot of comments and stuff, and I know that people, a lot of times will read the comments, and it really makes you see that everybody is really entitled to their own opinions and there are so many other opinions, but, at the end of the day, you just are going to read one thing and another thing and another thing, everyone can have something to say.

Preservice teachers further discussed specific MIL skills or practices that could positively impact students and help them learn to search and analyze information $(\mathrm{N}=11)$ as well as critically look at the media producing such information $(\mathrm{N}=16)$. Often, they associated these MIL skills with looking at digital media through a critical thinking lens $(\mathrm{N}=10)$, such as understanding the way others communicate through different media, detecting biases and authorial agendas, and being able to find additional resources to support one's opinion on particular topics were important for students to acquire.

Subjective norms. As students move through their teacher preparation program, they acknowledge that media and information literacy is not emphasized. A large majority of participants $(\mathrm{N}=18)$ emphasized the crucial role that teachers play in instructing students about MIL. However, participants who were juniors or seniors in their program $(\mathrm{N}=8)$ expressed mixed opinions about the emphasis on media \& information literacy education in their teacher education program. When asked whether their program stressed the importance of teaching MIL in their future classroom, the interviews revealed unconfident responses, particularly when participants distinguished between teaching with and about digital media. One preservice teacher disclosed that:

There is a lot of technology in our college-level classes and also they encourage others to use it in our placement classroom. I don't know if they are necessarily helping me to teach them [MIL skills], I do know that they are trying to get us to incorporate technology, they encourage that.

In a similar vein, another participant added that "it hasn't been explicitly said that we are focusing on media, but in most of my teacher education classes, they have all been showing how to use valuable tools." When asked directly about MIL and digital media, one preservice teacher admitted that "it hasn't been a concentrated idea so far," while another shared that "if you're talking about training on how to use it in the classroom, we haven't gotten too much of it." One participant conceded that: "it is more like a general skill that they assume you have." Nonetheless, some of the advanced preservice teachers shared insight 
about how they would have liked MIL to be taught in their program. For example, one of them described:

It's so helpful to have someone show me, because I know I wanted to be a teacher forever, but when it comes down to 'oh I'm gonna be teaching soon'...that's when the fear and anxiety happens. So, it's really helpful if someone could have modeled it [Media \& Information Literacy] and I'd know this is how I can do it and incorporate it into my classroom.

Likewise, a participant reflected back on her experience in the program as she concluded her interview: "I mean, that's how we learn to be teachers, we can't just be told to be a teacher, we have to observe good teachers [...] and with technology in the classroom, you have some that don't use it well as those who do, and you'll know 'that's how I want to do it." Preservice teachers, therefore, showcased a positive, yet hesitant view of the emphasis of MIL and MIL pedagogy in their program. Preservice teachers who were at the start of their teacher education program $(\mathrm{N}=11)$ also reported mixed feelings regarding their program's focus on Media \& Information Literacy. When asked if MIL had been emphasized in their program so far, four agreed, three responded negatively, and four were unsure.

Perceived Behavioral Control. Because most of the interviewed preservice teachers used technology on a daily basis - all subjects reported using social media every day to gather news or information-majority of them $(\mathrm{N}=18)$ revealed feeling comfortable and knowledgeable about digital media. Yet, many of them $(\mathrm{N}=17)$ also expressed concerns about not knowing how to teach MIL skills to their future students. One participant admitted: "I'm not confident, despite the fact that I'm experienced [in digital media]," while another participant disclosed that "I definitely feel that I have a grasp on how to utilize technology on a basic level whether it's social media or the Internet. But just sort of gaining a mastery over that [for teaching] would be beneficial." This sentiment was echoed by a participant who shared that "I feel I have some skills but maybe not all the skills that I would want."

Some of the beginning preservice teachers $(\mathrm{N}=8)$ expressed their desire for more MIL training in their teacher education program. One of them admitted that "we haven't talked about how to be safe on the Internet, how to teach students how to use the Internet." This participant in particular reflected on how her own instructors were using digital media in the classroom, yet she did not know how to transfer it to her own teaching:

This is a hard discussion because I've never thought about approaching media in the classroom, I would say it's beneficial but I would say that I am not learning how to use it in the classroom. I mean my teachers are using it but I am not learning how to use it, how to approach it. 
Other preservice teachers expressed similar concerns about the preparation of future teachers. One proposed that "I feel that it would be beneficial if they taught us...'these are some of the things that are beneficial that you can do with your students to get them ready to use the Internet." Similarly, another participant expressed what she would like to see in her program: "I guess explaining to us how we can show them what's right and what's wrong, 'cause I can't really tell you exactly what...'this is what they should be learning, this is what they should not be looking at."'

Overall preservice teachers expressed a lack of preparation to help them transfer their knowledge of digital media to MIL pedagogies that would benefit students. Their need for training (i.e., perceived behavioral control) was reflected in their uncertainty about the importance of MIL in their program (i.e., subjective norms), although a majority of preservice teachers valued MIL skills as beneficial for students' career and life readiness (i.e., attitude). This exploratory study served as a foundation for a follow-up study aiming to identify the salient beliefs underlying preservice teachers' intention to teach MIL in their future classroom.

\section{Study Two}

This elicitation study aimed to explore preservice teachers' beliefs regarding the teaching of media \& information literacy in their future classroom-namely behavioral beliefs, normative beliefs, and control beliefs, according to the theory of planned behavior. In this study, we asked: What behavioral, normative, and control beliefs do preservice teachers hold about teaching media \& information literacy in their future classroom?

Participants. The second study was conducted with three focus groups including four participants each, for a total of 12 participants. The participants represented a criterion sample, that is, a sample of individuals who fit a particular set of predetermined criteria to purposively look at the research question from the perspective of participants who would best represent it (Hatch 2002). In this case, we targeted individuals who were generally interested in technology-related issues in education. Participants were 12 female preservice teachers who had previously taken an elective introductory educational technology course where the concept of media \& information literacy had been introduced during a two-week module.

Measures. Elicitation studies are recommended in order to identify a target population's salient beliefs about a behavior when using the theory of planned behavior (Ajzen 1991; Downs and Hausenblas 2005; Francis et al. 2004). The protocol included six structured open-ended questions that participants discussed during the focus group (Appendix B). The three sets of questions aimed to elicit behavioral beliefs, normative beliefs, and control beliefs in relation to preservice teachers' intention to teach media literacy in their future classroom. Behavioral beliefs were elicited by (1) talking about the outcomes of teaching media \& information literacy and by asking participants to list benefits and disadvantages of teaching it in their future classroom. Normative beliefs were elicited by (2) talking about social referents who can have an influence on them teaching media \& information literacy and by asking participants who would 
approve or disapprove of them teaching it in their future classroom. Finally, control beliefs were elicited by (3) talking about circumstances surrounding the teaching of media \& information literacy and by asking them about facilitating factors and barriers that would make teaching it in their future classroom more easy or difficult.

Procedure. Participants were solicited via email to participate in a focus group about media and information literacy. Once potential participants expressed interest in the study, times were scheduled for the focus groups, which consisted of two groups of six participants each. The focus groups started with a brief description of MIL. Participants were asked to discuss the possibility of teaching MIL in their future classroom. It was emphasized that the researcher was interested in their opinions and that there were no right or wrong answers. The researcher moderated the discussion between the focus group participants using the interview questions. Each focus group lasted approximately 40 minutes. Participants were then compensated for their time with a twenty-dollar Amazon gift card.

Data analysis. Once the focus group answers were collected, a content analysis of their responses was performed in order to organize participants' responses into themes. Using the qualitative software NVivo, two researchers independently coded the content of participants' responses into themes. These themes were labeled and listed in order of frequency for each of the solicited behavioral beliefs, namely, attitudes, subjective norms, and perceived behavioral control. Inter-rater reliability was established at $83.3 \%$, with a Cohen's Kappa coefficient of .806 , an agreement deemed acceptable to validate the analysis. Responses were categorized based on common words, concepts, or themes to determine popular responses for each belief. For that purpose, we recorded the number of individual participants who mentioned these concepts, which was then represented both as frequency and as an overall percentage of participants who cited these factors (see table 1 below). The analysis resulted in a list of 44 factors. They were then translated into salient behavioral, normative, and control beliefs about preservice teachers teaching MIL in their future classroom. The list of factors was ranked-ordered and frequently mentioned items were selected as the salient set, as recommended by Ajzen (1991).

\section{Results}

Preservice teachers recognized the potential benefits and liabilities of media and information literacy and identified a number of stakeholders and other factors that might influence their willingness to incorporate it into their future work. Table 1 presents a summary of the most popular salient outcomes (advantages/disadvantages), social referents (approval/disapproval) and factors (facilitators/barriers) related to preservice teachers teaching MIL in their future classroom.

When asked about behavioral beliefs, the majority of the preservice teachers $(75 \%)$ mentioned helping students get ready for college as the biggest advantage to teaching media \& information literacy in their future classroom. Participants also discussed a number of other advantages, which included 
teaching students about Internet safety (58\%), helping students with their personal life $(50 \%)$, teaching students to evaluate information (33\%) and helping students conduct research and write papers (33\%). When discussing disadvantages of MIL,

Table 1. Salient behavioral, normative, and control beliefs about media and information literacy among pre-service teachers

\section{Frequency Percentage}

\section{OUTCOMES (behavioral beliefs)}

Advantages

Help students get ready for college 75

Teach students about Internet safety

Help students with their personal life

Teach students to evaluate information

Help students conduct research and write papers

Help students interact with others online

Teach students how to navigate media

Teach students to have educated opinions

$\begin{array}{rr}7 & 58 \\ 6 & 50 \\ 4 & 33 \\ 4 & 33 \\ 2 & 17 \\ 2 & 17 \\ 1 & 8\end{array}$

\section{Disadvantages}

$\begin{array}{lll}\text { Parents might disagree } & 8 & 67\end{array}$

$\begin{array}{lll}\text { Students will not use it at home } & 7 & 58\end{array}$

$\begin{array}{lll}\text { It takes time away from the curriculum } & 5 & 42\end{array}$

$\begin{array}{lll}\text { Students can misuse Internet at school } & 4\end{array}$

It could be taught in unsafe ways

It could make students dependent to technology

1

Students might think too much into it

$1 \quad 8$

1

\section{SOCIAL REFERENTS (normative beliefs)}

Approval

$\begin{array}{lll}\text { Intro to Ed Tech instructors } & 12 & 100\end{array}$

$\begin{array}{lll}\text { Teacher education faculty } & 10 & 83\end{array}$

$\begin{array}{lll}\text { Fellow students } & 9 & 75\end{array}$

$\begin{array}{lll}\text { Inservice teachers } & 7 & 58\end{array}$

$\begin{array}{lll}\text { People who know about MIL } & 6 & 50\end{array}$

$\begin{array}{lll}\text { Young parents } & 6 & 50\end{array}$

$\begin{array}{lll}\text { Administrative staff } & 2 & 17\end{array}$

Recent graduates $\quad 1 \quad 8$

Tech support staff $\quad 1 \quad 8$

Disapproval

$\begin{array}{lll}\text { Older generation of professors } & 8 & 67\end{array}$

$\begin{array}{lll}\text { Principals who are against technology } & 7 & 58\end{array}$ 


\begin{tabular}{lrr} 
Parents who are against social media & 6 & 50 \\
People who don't know about MIL & 6 & 50 \\
Administrators who don't want to change & 4 & 33 \\
Families with no computers & 2 & 17 \\
People who had bad MIL experiences & 1 & 8 \\
& & \\
\hline FACTORS (control beliefs) & & \\
\hline Facilitators & 7 & 58 \\
Being familiar with MIL & 6 & 50 \\
Having teachers modeling MI & 5 & 42 \\
Having MIL in the curriculum & 5 & 42 \\
Having district funding for technology & 4 & 33 \\
Having available resources & & \\
& & \\
Barriers & 8 & 67 \\
Teaching in a poor district & 7 & 58 \\
Not having technology available & 5 & 42 \\
If administrators are against MIL & 4 & 33 \\
Students knowing more technology than teachers & 4 & 33 \\
Students not using media literacy at home & 3 & 25 \\
If students don't see MIL as a priority & 2 & 17 \\
Parents not implementing MIL at home & 1 & 8 \\
If students are not at grade level & &
\end{tabular}

the biggest theme participants discussed was that parents might disagree (67\%). In addition, preservice teachers also identified other disadvantages of teaching MIL in their future classroom, including students will not use MIL at home (58\%), it takes time away from the curriculum (42\%) and students can misuse Internet at school (33\%).

In terms of normative beliefs, preservice teachers frequently indicated faculty and instructors as salient social referents. Course instructors (from the introduction to educational technology course where MIL was taught) were the most frequently mentioned approving referents; they were reported by $100 \%$ of the participants. Teacher education faculty (83\%), fellow students (75\%), inservice teachers $(58 \%)$, people who know about MIL (50\%) and young parents $(50 \%)$ were also mentioned as positive social referents. A significant number of preservice teachers $(67 \%)$ mentioned the older generation of professors as the most disapproving group, followed by principals against technology (58\%), parents against social media (50\%) and people who don't know about MIL (50\%). Is media literacy controversial among parents? It's noteworthy that some participants thought that parents would be supportive (50\%) and others thought they would be disapproving of it $(50 \%)$. 
In terms of control beliefs, $58 \%$ of the preservice teachers alluded to being familiar with MIL as a facilitator for teaching MIL. They also added having teachers modeling MIL (50\%), having MIL in the curriculum (42\%), having district funding for technology (42\%) and having available resources (33\%) as facilitators for teaching MIL in their future classroom. On the other hand, teaching in a poor district was the most frequently reported barrier by $67 \%$ of the participants. Similarly, $58 \%$ of the preservice teachers reported not having technology available (58\%), administrators against MIL (42\%), students knowing more technology than teachers (33\%) and students not using MIL at home (33\%) as barriers for teaching MIL in their future classroom.

\section{Discussion}

The theory of planned behavior explains that the extent to which individuals view a particular behavior (i.e., attitude), think that others also want them to engage in said behavior (i.e., subjective norms), and think that they know how to perform the behavior (i.e., perceived behavioral control), serve as direct determinants of the strength of their intention to carry out the behavior (Ajzen 1991). The first study explored the direct factors influencing preservice teachers' perspectives towards teaching MIL in their future classroom. Results from the first study suggested that preservice teachers have positive attitudes towards MIL. Indeed, results from the first study interviews exhibited that preservice teachers valued the relevance of MIL for students and understood its benefits both for career and life readiness. They agreed that teachers play a central role in helping students decipher the veracity of digital information, and that being media and information literate had become a necessity in students' lives.

In terms of subjective norms, participants' responses became less certain when discussing how others - faculty and instructors in particular-engaged in teaching them about MIL in their program. A majority of preservice teachers expressed that although technology use was encouraged in their teacher preparation program, emphasis was placed on teaching with technology and not necessarily about technology. They also noted that a focus on MIL-related skills was generally not explicit in their program, that variations existed depending on instructors, and that it was often assumed that they already possessed these skills. Finally, the interviews helped reveal preservice teachers' perceived behavioral control in relation to MIL. While a majority of them expressed being comfortable with technology through their personal use of digital and social media, the same majority admitted not knowing how to teach MIL skills to students. As a result, they overwhelmingly expressed a desire to receive more training in MIL-related skills in their program, and to have instructors model these pedagogies for them.

The theory of planned behavior further adds that each of the three determinants of behavioral intention (i.e., attitude, subjective norms, and perceived behavioral control) is influenced by an indirect determinant based on a set of salient beliefs about the behavior at hand. In the second study, these beliefs were elicited to understand preservice teachers' underlying beliefs about teaching MIL in their future classroom. Results about their behavioral beliefs showed that 
they viewed MIL as a beneficial skill to help students be prepared for college as well as their personal life.

Nevertheless, these positive beliefs were counterbalanced by more negative ones about teaching MIL in their future classroom, such as parents disagreeing with that decision, students not using these skills at home or misusing the Internet at school, or MIL taking time away from teaching content. An analysis of participants' normative beliefs showed that faculty and instructors were the main social referents for preservice teachers when it came to teaching MIL. More specifically, preservice teachers identified instructors of a course that covered MIL as people who would most approve of them teaching MIL in their future classroom. Outside of their program, inservice teachers, young parents, and overall people who know about MIL seemed to be groups of people who would positively see MIL in the classroom. On the contrary, they identified professors from older generations, administrators against technology, and parents against social media as individuals who would not support their choice of teaching MIL. Interestingly, these referents were mentioned both as groups who could either approve and disapprove of that choice.

Finally, participants' perceived control beliefs reflected that they viewed knowledge and modeling of MIL, as well as curriculum, funding, and resources as factors that would help them teach MIL; while lack of funding, administrators against MIL, students not using MIL at home and them knowing more about technology than teachers were viewed by preservice teachers as factors that would make it more difficult to teach MIL in their future classroom.

\section{Implications and Future Directions}

Findings from these studies have both practical and theoretical implications for future work aiming to examine ways to prepare preservice teachers to embed MIL in their future classroom. For researchers, this phase of formative research served two purposes. First, the qualitative data provided an understanding of the perspectives and beliefs that preservice teachers have about teaching MIL in their future classroom, which can be incorporated into designing effective intervention programs. Second, the information can be used to develop a quantitative instrument to examine the relative importance of both the direct determinants and salient beliefs about the behavior in a larger-scale study, which can provide directions for future media $\&$ information literacy education efforts. Both these practical and theoretical implications would not only respond to the current need to teach students MIL skills, but will also strengthen preservice teachers' intention to teach MIL to their students.

For teacher educators, the studies demonstrate the need to explicitly integrate MIL into teacher preparation programs, so that preservice teachers are not only exposed to the concept, but also become knowledgeable about how to embed it in their future classroom. Results from the studies demonstrate that preservice teachers' have the desire to learn more about how to teach MIL. The research literature identifies the specific competencies preservice teachers should possess in order to embed digital media and MIL in their classroom (Kovalik, 
Kuo and Karpinski 2013; Schieble 2010; Thompson, Schmidt-Crawford and Lindstrom 2015; Tondeur et al. 2012; Wiseman 2012).

The findings also suggested that teacher educators should capitalize on preservice teachers' positive attitudes as a starting point to introduce MIL pedagogies. As a first step towards this goal, we need to further understand preservice teachers' identities as digital educators and how their attitudes towards mass media, digital culture and social media can influence their motivations to use them for teaching and learning purposes (Hobbs and Tuzel 2017). Future work should explore preservice teachers' personal use of digital media and information in their personal lives to investigate how that personal use may or may not transfer to their own pedagogy (Carr 2010). Moreover, the findings showed a need for teacher educators to help preservice teachers understand how different factors could enhance or impede the teaching of MIL in their future classroom (e.g., resources, funding). This could help dismiss misconceptions and address potential challenges to strengthen preservice teachers' intention to do so, and help reinforce their positive attitudes towards using MIL while bolstering their proficiency and confidence in using it (Lei 2009).

The findings suggested that preservice teachers highly valued the opinion of faculty and instructors, which has important implications for teacher educators. One way to develop preservice teachers' digital wisdom (Prensky 2009) and intention to teach MIL is for teacher educators to model teaching with and about technology in their own teacher education coursework (Tiede et al. 2015). Previous research has suggested that when teacher educators successfully integrate digital media in teacher education classes, preservice teachers are more likely to replicate such use on their own (Yilmazel-Sahin and Oxford 2010). Furthermore, modeling by expert teachers has been found to be an effective approach at giving preservice teachers ideas to implement in the classroom (Vannatta 2000; West and Graham 2007), and such modeling, or lack thereof, can also significantly influence preservice teachers' use of digital media in classroom instruction (Brown and Warschauer 2006; Vrasida and McIsaac 2001).

In addition, another important finding was that preservice teachers considered their instructors from an elective educational technology course in which they covered MIL concepts to be positive social referents when thinking about teaching MIL in their future classroom. Teacher education programs should consider the benefits of such introductory or elective educational technology courses as ways to introduce MIL to preservice teachers (Polly, Mims, Shepherd and Inan 2009). The UNESCO, for instance, has designed a MIL curriculum for teacher that includes adaptable module-based curriculum to introduce MIL to teachers (Grizzle et al. 2013), which could be integrated in such courses. As preservice teachers develop an understanding of MIL concepts in educational technology courses, they could learn to apply MIL to other classes (Kleiner, Thomas and Lewis 2007) and learn about MIL within the context of their specific subject area. Consequently, future work in this area should look more specifically at the effects of brief MIL exposure and training for preservice teachers (Pérez Tornero 2008).

Together, these studies had some limitations that should be acknowledged 
when considering their findings. One of the limitations was that while qualitative research can provide an in-depth understanding of participants' perspectives on a specific issue, qualitative data from a small number of participants limits generalizability to the larger population of preservice teachers in the United States. Another limitation of this study was that it was conducted in a single institution at a large Midwestern university. Hence, researchers interested in examining preservice teachers' perspectives towards teaching MIL in their own settings should take into account the particular context of the present study. Nevertheless, given the ability for the TPB model to predict preservice teachers' intentions to use and teach with technology (Sadaf, Newby and Ertmer 2012; Shiue 2007; Teo and Lee 2010; Teo 2012; Valtonen et al. 2015), findings from this set of studies raise new questions for teacher educators and researchers interested in developing and measuring preservice teachers' intentions to teach MIL in their future classroom.

The present set of studies identified direct determinants and elicited underlying beliefs related to preservice teachers' views of teaching media \& information literacy in their future classroom. Knowledge of these factors, along with their salient beliefs, provides a foundation for teacher educators to promote the behavior in question. In addition, a measurement instrument derived from the present results can serve as a model for quantitative research on preservice teachers' intentions to teach media \& information literacy in response to the need for students to possess these skills in the digital age.

\section{References}

Ajzen, Icek. 1991. "The Theory of Planned Behavior.” Organizational Behavior and Human Decision Processes, 50(2): 179-211.

Boulianne, Shelley. 2015. "Social Media Use and Participation: A Meta-Analysis of Current Research." Information, Communication \& Society 18 (5): 524538.

Brown, Diana, and Mark Warschauer. 2006. "From the University to the Elementary Classroom: Students' Experiences in Learning to Integrate Technology in Instruction." Journal of Technology and Teacher Education 14 (3): 599-621.

Carr, Nicola. 2010. “Are we Teaching Digital Natives yet-and Does it Matter?" AARE International Education Research Conference: 1-14.

Charmaz, Kathy. 2006. Constructing Grounded Theory: A Practical Guide through Qualitative Analysis. Thousand Oaks, CA: Sage.

Creswell, John W. 2013. Qualitative Inquiry and Research Design: Choosing among Five Traditions ( $3^{\text {rd }}$ ed). Thousand Oaks, CA: Sage.

Downs, Danielle Symons, and Heather A. Hausenblas. 2005. "Elicitation Studies and the Theory of Planned Behavior: A Systematic Review of Exercise Beliefs." Psychology of Sport and Exercise 6(1): 1-31.

Earp, Vanessa. 2009. "Integrating Information Literacy into Teacher Education: A Successful Grant Project.” Behavioral \& Social Sciences Librarian 28 (4): 166-178. 
Francis, Jillian, Martin P. Eccles, Marie Johnston, A. E. Walker, J. M. Grimshaw, Robbie Foy, Eileen FS Kaner, Liz Smith, and Debbie Bonetti. 2004. Constructing Questionnaires based on the Theory of Planned Behaviour: A Manual for Health Services Researchers. Newcastle upon Tyne, UK: Centre for Health Services Research, University of Newcastle upon Tyne. Grizzle, Alton, Penny Moore, Michael Dezuanni, Sanjay Asthana, Carolyn Wilson, Fackson Banda, and Chido Onumah. 2013. Media and Information Literacy: Policy and Strategy Guidelines. UNESCO. Retrieved from http://unesdoc.unesco.org/images/0022/002256/225606e.pdf

Hargittai, Eszter. 2010. "Digital Na (t) ives? Variation in Internet Skills and Uses among Members of the "Net Generation." Sociological inquiry, 80 (1): 92-113.

Hatch, J. Amos. 2002. Doing Qualitative Research in Education Settings. Buffalo, NY: SUNY Press.

Hobbs, Renee. 2007. "Approaches to Instruction and Teacher Education in Media Literacy." Higher Education Research \& Evaluation: 58-64.

Hobbs, Renee, and Sait Tuzel. 2017. "Teacher Motivations for Digital and Media Literacy: An Examination of Turkish Educators.” British Journal of Educational Technology: 48(1), 7 - 22. DOI: 10.1111/bjet.12326

Hoffman, J. V., Melissa B. Wilson, Ramon A. Martínez, and Misty Sailors. 2011. "Content Analysis: The Past, Present, and Future." In Literacy Research Methodologies (2nd ed), edited by Duke Nell. K. and Marla H. Mallette, 28-49. New York, NY: Guilford.

International Society for Technology in Education (ISTE). 2015. ISTE Standards for Students. Retrieved from: https://www.iste.org/docs/pdfs/2014_ISTE_Standards-S_PDF.pdf

Kinash, Shelley, Kayleen Wood, and Diana Knight. 2013. "Digital Immigrant Teachers and Digital Native Students: What Happens to Teaching?" Learning and Teaching papers. Paper 50. Retrieved from: http://epublications.bond.edu.au/cgi/viewcontent.cgi?article=1049\&contex $\underline{\mathrm{t}=\mathrm{tls}}$

Kleiner, Brian, Nina Thomas, and Laurie Lewis. 2007. Educational Technology in Teacher Education Programs for Initial Licensure. Statistical Analysis Report. NCES 2008-040. National Center for Education Statistics. Retrieved from: https://nces.ed.gov/pubs2008/2008040.pdf

Kovalik, Cindy, Mary Lee Jensen, Babarda Schloman, and Mary Tipton. 2011. "Information Literacy, Collaboration, and Teacher Education." Communications in Information Literacy 4 (2): 145-169.

Lee, Jung, Cerreto, Frank, \& Lee, Jihyun. 2010. "Theory of Planned Behavior and Teachers' Decisions Regarding Use of Educational Technology."

Educational Technology \& Society, 13 (1): 152-164.

Lei, Jing. 2009. "Digital Natives as Preservice Teachers: What Technology Preparation is Needed?" Journal of Computing in Teacher Education 25 (3): 87-97. 
Lenhart, Amanda. 2015. Teens, Social Media and Technology Overview 2015. Washington DC: Pew Research Center. Retrieved from: http://www.pewinternet.org/files/2015/04/PI_TeensandTech_Update2015 _0409151.pdf

Lindstrom, Denise, Denise Schmidt-Crawford, and Ann D. Thompson. 2016. "New Literacies, Technology, and Teacher Beliefs: Still More Work to Do." Journal of Digital Learning in Teacher Education 32 (1): 3-4.

Mason, Mark. 2010. "Sample Size and Saturation in PhD Studies Using Qualitative Interviews.” Forum: Qualitative Social Research 11 (3): 1-19. National Council for the Social Studies. 2013. The College, Career, and Civic Life (C3) Framework for Social Studies State Standards: Guidance for Enhancing the Rigor of K-12 Civics, Economics, Geography, and History. Retrieved from: http://www.socialstudies.org/system/files/c3/C3Framework-for-Social-Studies.pdf

National Governors Association Center for Best Practices, Council of Chief State School. 2010. Common Core State Standards for English Language Arts. Retrieved from: http://www.corestandards.org/ELA-Literacy/

Next Generation Science Standards Lead States. 2013. Next Generation Science Standards: For States, By States. Washington, DC: National Academies Press.

Partnership for $21^{\text {st }}$ Century Skills. 2014. Framework for State Action on Global Education. Retrieved from: http://www.p21.org/storage/documents/Global_Education/P21_State_Fra mework_on_Global_Education.pdf

Pérez Tornero, J. M. 2008. Teacher Training Curricula for Media and Information Literacy. UNESCO International Expert Group Meeting. Retrieved from: http://portal.unesco.org/ci/en/ev.phpURL_ID=27508\&URL_DO=DO_TOPIC\&URL_SECTION=201.html

Polly, Drew, Clif Mims, Craig E. Shepherd, and Fethi Inan. 2010. "Evidence of Impact: Transforming Teacher Education with Preparing Tomorrow's Teachers to Teach with Technology (PT3) Grants." Teaching and Teacher Education 26 (4): 863-870.

Prensky, Marc. 2009. “H. Sapiens Digital: From Digital Immigrants and Digital Natives to Digital Wisdom." Innovate: Journal of Online Education 5 (3): $1-10$.

Russell, Michael, Daminan Bebell, Laura O’Dwyer, and Kathleen O'Connor. 2003. "Examining Teacher Technology Use: Implications for Preservice and Inservice Teacher Preparation." Journal of Teacher Education 54 (4): 297-310.

Sadaf, Ayesha, Timothy J. Newby, and Peggy A. Ertmer. 2012. "Exploring Factors that Predict Preservice Teachers' Intentions to Use Web 2.0 Technologies Using Decomposed Theory of Planned Behavior.” Journal of Research on Technology in Education, 45(2): 171-196.

Schieble, Melissa. 2010. "The Not so Digital Divide: Bringing Pre-service English Teachers' Media Literacies into Practice.” Journal of Media Literacy Education 2 (2): 102-112. 
Shiue, Ya-Ming., 2007. "Investigating the Sources of Teachers' Instructional Technology Use through the Decomposed Theory of Planned Behavior. Journal of Educational Computing Research, 36(4): 425-453.

Smarkola, Claudia. 2008. "Efficacy of a Planned Behavior Model: Beliefs that Contribute to Computer Usage Intentions of Student Teachers and Experienced Teachers." Computers in Human Behavior, 24(3): 11961215.

Stanford History Education Group. 2016. "Evaluating information: The Cornerstone of Civic Online Reasoning," Retrieved from: https://sheg.stanford.edu/upload/V3LessonPlans/Executive\%20Summary \%2011.21.16.pdf

Teo, Timothy and Beng Lee, Chwee. 2010. "Explaining the Intention to Use Technology among Student Teachers: An Application of the Theory of Planned Behavior (TPB). Campus Wide Information Systems, 27(2): 6067.

Teo, Timothy and Tan, Lynde. 2012. "The Theory of Planned Behavior (TPB) and Preservice Teachers' Technology Acceptance: A Validation Study Using Structural Equation Modeling." Journal of Technology and Teacher Education, 20(1): 89-104.

Thompson, Ann D., Denise Schmidt-Crawford, and Denise Lindstrom. 2015. “Are We Finished Yet?" Journal of Digital Learning in Teacher Education 31 (4): 133-133.

Tiede, Jennifer, Silke Grafe, and Renee Hobbs. 2015. "Pedagogical Media Competencies of Preservice Teachers in Germany and the United States: Comparative Analysis of Theory/Practice." Peabody Journal of Education 90 (4), 533-545.

Tondeur, Jo, Johan van Braak, Guoyuan Sang, Joke Voogt, Petra Fisser, and Anne Ottenbreit Leftwich. 2012. "Preparing Preservice Teachers to Integrate Technology in Education: A Synthesis of Qualitative Evidence." Computers \& Education 59: 134-144.

Valtonen, Teemu, Jari Kukkonen, Sini Kontkanen, Kari Sormunen, Patrick Dillon, and Erkko Sointu. 2015. "The Impact of Authentic Learning Experiences with ICT on Preservice Teachers' Intention to use ICT for Teaching and Learning." Computers \& Education, 81: 49-58.

Vannatta, Rachel A. 2000. "Integrating, Infusing, Modeling: Preparing Technology-Using Educators." Journal of Computing in Teacher Education 16 (2): 6-14.

Vrasida, Charalambos, and Marina S. McIsaac. 2001. "Integrating Technology into Teaching and Teacher Education: Implications for Policy and Curriculum Reform.” Educational Media International 2 (3): 127-132.

West, Richard E., and Charles R. Graham. 2007. "Benefits and Challenges of Using Live Modeling to Help Preservice Teachers Transfer Technology Integration Principles." Journal of Computing in Teacher Education 23 (4): 131-141.

Wilson, Carolyn, Alton Grizzle, Ramon Tuazon, Kwame Akyempong, and Chi K. Cheung. 2013. Media and Information Literacy Curriculum for Teachers. 
UNESCO. Retrieved from:

http://www.unesco.org/new/en/communication-and-

information/resources/publications-and-communication-

materials/publications/full-list/media-and-information-literacy-curriculumfor-teachers/

Wiseman, Donna L. 2012. "The Intersection of Policy, Reform, and Teacher Education." Journal of Teacher Education 63 (2): 87-91.

Yilmazel-Sahin, Yesim, and Rebecca L. Oxford. 2010. "A Comparative Analysis of Teacher Education Faculty Development Models for Technology Integration.” Journal of Technology and Teacher Education 18 (4): 693720 . 


\section{Appendix A \\ Interview and Focus Group Questions}

\section{Interview Items}

Eliciting attitudes

What are your general thoughts after hearing the definition of media literacy?

Why do you think students should or should not be media literate?

Eliciting subjective norms

Has there been an explicit focus on media literacy in your program?

How is the importance of media literacy reflected by professors, peers, etc in your program?

\section{Eliciting perceived behavioral control}

How has your teacher preparation program trained you to integrate MIL and/or technology in your future classroom?

Do you feel that you have the necessary tools/resources that you would need to teach media literacy in your future classroom?

\section{Focus Group Discussion Items}

Behavioral outcomes. There are many perspectives about teaching media literacy in the classroom.

1) What do you see as the advantages of teaching MIL in your future classroom?

2) What do you see as the disadvantages of teaching MIL in your future classroom?

Normative referents. When it comes to teaching MIL in your future classroom, there might be individuals or groups who would think you should or should not perform this behavior.

1) Please list the individuals or groups who would approve of you teaching MIL in your future classroom.

2) Please list the individuals or groups who would disapprove of you teaching MIL in your future classroom.

Control factors. When it comes to practical aspects of teaching MIL in your future classroom, there might or things that would make it easier to do it or challenges that might impede you to do it.

1) Please list any factors or circumstances that would facilitate the teaching of MIL in your future classroom.

2) Please list any factors or circumstances that would be a barrier for you to teach MIL in your future classroom. 